\title{
Continuous Fuzzy Kano Model and Fuzzy AHP Model for Aesthetic Product Design: Case Study of an Electric Scooter
}

\author{
Yixiang Wu (D) and Jianxin Cheng (D) \\ East China University of Science and Technology, 130 Meilong Road, Xuhui District, Shanghai 200237, China \\ Correspondence should be addressed to Yixiang Wu; 17317136949@163.com and Jianxin Cheng; 13901633292@163.com
}

Received 31 May 2018; Revised 14 August 2018; Accepted 29 August 2018; Published 20 September 2018

Academic Editor: Sitek Paweł

Copyright (c) 2018 Yixiang Wu and Jianxin Cheng. This is an open access article distributed under the Creative Commons Attribution License, which permits unrestricted use, distribution, and reproduction in any medium, provided the original work is properly cited.

\begin{abstract}
The fuzzy Kano model (FKM) adopts a linear scoring system that cannot accurately reflect the relationship between users' needs and satisfaction and may underestimate the importance of users' evaluation and needs. In this paper, we propose a preference-based evaluation-fuzzy-quantification method to determine the priority of the development of attractive factors of an electric scooter. In the evaluation analysis stage, the evaluation grid diagrams of all the interviewees are systemized. In the fuzzy computing stage, the continuous fuzzy Kano model (C-FKM) combined with the fuzzy analytic hierarchy process (FAHP) is developed to determine the priority of the development of attractive factors. By processing the ambiguity of users' needs, the C-FKM can obtain a more accurate representation of users' needs than the FKM. The opinions of 20 experts are integrated using the similarity aggregation method (SAM); then the FAHP is applied to calculate the weight of each evaluation criterion. Lastly, we use quantitative analysis to discover the important and specific characteristics that influence the attractiveness of an electric scooter. Research shows that Kansei images with attractive qualities are reliable and may be the first choice for satisfying the perceptual demands of consumers and can provide reference for the related research.
\end{abstract}

\section{Introduction}

In the field of product design, the study of the correlation between Kansei engineering [1] and the Kano model [2] has been vigorously advocated, and the subjective emotion of the consumer has been valued. As a technology for new product development oriented to a consumer's feelings, Kansei engineering was defined as an art which embodies the feeling or image of the consumer of the product into the design elements and has been successfully applied to product design to explore the relationship between a consumer's feelings and product design [1]. Kansei was a Japanese word that meant a consumer's psychological feeling and image of a new product [3]. Kansei is usually expressed via adjectives rich in emotional connotations, for example, beautiful, romantic, fantastic, and comfortable [4]. The Kansei image is a consumer-oriented concept, and it is a type of psychological sensation of a product from consumers' cognition of emotion [5]. Obtaining the related information for a product's Kansei image is helpful for designers to orientate a new product during the process of product design [6]. Kansei images are depicted as the set of Kansei words [7]. Consumers' emotional demands can be described via the forms of Kansei image preference and Kansei image weight [7]. Smith and Fu [8] explored the relationship between the presentation image designs of an instrument panel and drivers' Kansei images, so as to build a prediction model that describes the relationship between the representative Kansei images and physical image design properties of the instrument panel. Tang et al. [9] put forward a set of methods to the product image survey and retrieval based on Kansei engineering. To consolidate consumers' emotional requirements, Kansei engineering advocators suggested a new perspective on human emotions-the use of Kansei words or adjectives to represent various emotions [10]. Kansei engineering is used to investigate the relationship between product design elements and Kansei images. The general idea is to select representative adjectives from numerous vocabularies. Then, combined with experimental samples, a semantic differential method is applied to ask for a customer's feelings. However, this type of score 
reflects only a consumer's feelings about a particular product; it does not really reflect the preference for the product. Thus, products that are designed according to the resulting product design procedure had a limited capability for controlling consumer satisfaction.

In the course of innovation and new product development, evaluating consumer demands using the Kano model should be an important component. Kano et al. [2] developed a two-dimensional diagram to present the relationship between consumer satisfaction and fulfilling demand degree. On the basis of consumer reaction, indexes are categorized with the Kano model as "Must-Be," "one-dimensional," and "attractive" qualities. Ted [11] classified the emotional demand levels of the modeling design as the basic level, the expectation level, and the excitement level, based on the Kano model classification method. Yadav et al. [12] evaluated the artistic attributes of automobile shape and asked testees to evaluate twelve artistic attributes that impact the shape of an automobile using a Kano two-way questionnaire. For customers who are not sure about their answers to a certain product attribute, investigation data achieved using the Kano model is not accurate [13]. Lee and Huang [13] developed the Fuzzy Kano Model Questionnaire. Compared with the traditional Kano model, the Fuzzy Kano Model Questionnaire can express consumer feelings better and assist designers in understanding consumer demand more accurately.

The fuzzy Kano model (FKM) can assist designers to understand users' demands more accurately; however, this mode is still a method of qualitative analysis, so that the method cannot solve the fuzzy continuity problem [14]. The FKM cannot accurately reflect the relationship between user demand and satisfaction; furthermore, this type of linear scoring system may weaken the importance of user evaluation and user demand. In addition, due to the insufficient judgement accuracy of the FKM, it may cause the designer's deviation from the real attention and focus of user demand, thus resulting in adverse factors of the product competition. Chen and Ko [15] suggested an "influence value" to show the contribution of each combination to a user's satisfaction. It is found that, in the Kano model evaluation table (Table 1) [16], different "influence values" can be given by the 25 combinations. Wu and Wang [14] developed a continuous fuzzy Kano model (C-FKM) to analyze user demand more accurately. Furthermore, research results show that the FKM cannot be used to accurately judge the quality attribute category of a user's demand for mobile phone functions. The $\mathrm{C}-\mathrm{FKM}$ is a more accurate analysis method for user demand of quantitative analysis [14]. As there is insufficient accuracy in the user's Kansei image via the traditional Kano model and the FKM, there is limited research literature on the Kansei images of products based on the C-FKM. Therefore, in this paper, we analyze the relationship between the customer's Kansei image and satisfaction toward products based on the C-FKM, thus helping designers to analyze users' preferences more accurately during the product development process.

Hartono and Chuan [17] described how the Kano model was helpful in Kansei engineering of services; they also introduced a comprehensive framework consisting of the Kano model and Kansei engineering. Tama et al. [18] combined Kansei engineering and the Kano model in their study to improve the design of ceramic souvenirs and better meet consumer expectations. During the study, they categorized or sorted emotion adjectives in accordance with the Kano model, and they calculated and analyzed the emotion adjectives which most affected consumer satisfaction and developed such adjectives as the key for further design [18]. Llinares and Page [19] suggested that the Kano model be incorporated into Kansei engineering while studying different influences of consumer feelings (emotion adjectives) on real estate buying decisions. Laarhoven and Pedrycz [20] proposed a fuzzy analytic hierarchy process (FAHP). Using an FAHP, $\mathrm{Tu}$ and $\mathrm{Hu}$ [21] constructed the Product Innovative Service System of Wedding Photography Apparel. Banihashemi et al. [22] evaluated digital identity management systems using an FAHP. Chyu and Fang [23] proposed a fuzzy analytic network process for solving the problem of product development selection. In the proposed model, the FKM is employed to establish interactions, and the similarity aggregation method (SAM) [24] is applied to integrate experts' opinions.

In this paper, we propose a preference-based evaluationfuzzy-quantification method to determine the priority of Kansei images of an electric scooter. Based on the previous research in the area of Kansei images, we find that there are still some shortcomings in using the Kano model to improve user satisfaction. Additionally, since the FAHP is just a linear weighting method, it is not the most appropriate solution. In the perceptual expressing behavior of the consumers, a priority order exists for the consumers' preferences to Kansei images. In other words, the emphasis on the different Kansei images determines the influences on the perceptual satisfaction of the consumers.

\section{Method}

2.1. The Evaluation Analysis Stage. To develop attractive products, Sanui and Inui [25] introduced the evaluation grid method (EGM) with reference to concepts in The Psychology of Personal Constructs by the clinical psychologist George Kelly [26]. The advantage of the EGM is that the structure of users' preferences can be elicited [27]. The EGM is a qualitative method used to analyze the influence of design factors and can be used to build the abstract feelings of interviewees [28].

The procedure for applying the EMG to explore the preferences for an electric scooter is as follows. Collect pictures of an electric scooter and invite interviewees to discuss them according to the EGM. Firstly, the interviewees need to pick out the attractive samples based on their own feelings and explain the causes of the attractions; these causes are the primary evaluation. Then, specific to each primary evaluation, the interviewees are continuously inquired regarding their own inner feelings (Kansei images). The interviewees can describe their own Kansei images to the products via enumeration of 1-3 Kansei words, for example, "fashionable," "smooth," and "modern." Finally, the interviewees are constantly inquired as to what the concrete characteristics of the attractive products are. The above process is repeated to obtain a hierarchical diagram on the interviewees' inner 
TABLE 1: Kano evaluation table.

\begin{tabular}{|c|c|c|c|c|c|}
\hline \multirow{2}{*}{ Functional } & \multicolumn{5}{|c|}{ Dysfunctional } \\
\hline & 1. Enjoy & 2. Except & 3. Neutral & 4. Live with & 5. Dislike \\
\hline 1. Enjoy & Q & A & $\mathrm{A}$ & A & $\mathrm{O}$ \\
\hline 2. Except & $\mathrm{R}$ & I & I & I & M \\
\hline 3. Neutral & $\mathrm{R}$ & I & I & I & M \\
\hline 4. Live with & $\mathrm{R}$ & I & I & I & M \\
\hline 5. Dislike & $\mathrm{R}$ & $\mathrm{R}$ & $\mathrm{R}$ & $\mathrm{R}$ & Q \\
\hline
\end{tabular}

Note: A: attractive; M: Must-Be; R: reverse. O: one-dimensional; Q: questionable; I: indifferent.

feelings toward the samples. The author simplifies the Kansei words via group discussion and merges these words based on their similarity. The evaluation grids of all the interviewees are summarized and the evaluation grid diagrams of all the interviewers are concluded, as shown in Figure $1[29,30]$.

\subsection{The Fuzzy Computing Stage}

2.2.1. Calculation of Kansei Image Weights by the SAM and FAHP. The SAM [24] is applied to calculate the consensus degree coefficient (CDC) of each specialist, so as to integrate the fuzzy evaluation value of the specialist and to obtain the significance comparison fuzzy values of any two criteria $a$ and $b$. This procedure is summarized by the following steps [24].

Step 1. Calculate the agreement degree $\left(S\left(\tilde{R}_{p}, \tilde{R}_{q}\right)\right)$ of any two specialists and establish an identity matrix. The calculation process is given by

$$
S\left(\tilde{R_{p}}, \tilde{R}_{q}\right)=\frac{\int_{x}\left(\min \left\{\mu_{\tilde{R}_{p}}(x), \mu_{\tilde{R}_{q}}(x)\right\}\right) d x}{\int_{x}\left(\max \left\{\mu_{\tilde{R}_{p}}(x), \mu_{\tilde{R}_{q}}(x)\right\}\right) d x}
$$

where $S\left(\tilde{R}_{p}, \tilde{R}_{q}\right)$ is the agreement degree of the fuzzy evaluation values of the $p$ th and $q$ th specialists; $\widetilde{R}_{p}, \widetilde{R}_{q}$ are the fuzzy evaluation values of the $p$ th and $q$ th specialists; and $\mu_{\tilde{R}_{p}}(x)$, $\mu_{\tilde{R}_{q}}(x)$ are the membership functions of the fuzzy evaluation values of the $p$ th and $q$ th specialists. Based on the agreement degree, build an agreement matrix $(A M)$, which is expressed as

$$
A M=\left|S_{p q}\right|_{n \times n}, \quad p q=1,2, \ldots, n
$$

such that if $p=q, S_{p q}=1$, whereas $S_{p q}=S\left(\tilde{R}_{p}^{\sim}, \tilde{R}_{q}\right)$.

Step 2. $A M$ is applied to calculate the mean agreement degree $\left(A\left(E_{p}\right)\right)$ of each specialist $p$.

$$
A\left(E_{p}\right)=\frac{1}{n-1} \sum_{\substack{p=1 \\ p \neq q}}^{n} S_{p q} ; \quad p, q=1,2, \ldots, n
$$

The mean agreement degree is applied to calculate the relative agreement degree $\left(R A D_{p}\right)$ of each specialist $p$ :

$$
R A D_{p}=\frac{A\left(E_{p}\right)}{\sum_{p=1}^{n} A\left(E_{p}\right)}, \quad p, q=1,2, \ldots, n
$$

Step 3. Calculate the CDC of each specialist expert $\mathrm{E}_{p}(p=1$, $2, \ldots, n)$ as

$$
\begin{aligned}
C D C_{p}=\beta \times w_{p}+(1-\beta) \times R A D_{p}, & \\
& p, q=1,2, \ldots, n
\end{aligned}
$$

where $0 \leq \beta \leq 1$. In this study, we do not consider the degree of importance of each expert $(\beta=0)$. Next, integrate the fuzzy evaluation values of all experts. For any two criteria or subcriteria $a$ and $b, \widetilde{R}_{a b}$ is a fuzzy number resulting from combining an expert's opinion, $\widetilde{R}_{a b}^{p}$, and the $p$ th expert's fuzzy evaluation value given by appraising the two criteria or subcriteria $a$ and $b$.

$$
\widetilde{R}_{a b}=\sum_{p=1}^{n} C D C_{P} \otimes \widetilde{R}_{a b}^{p}, \quad p, q=1,2 \ldots n
$$

The SAM can be used to calculate the fuzzy number of any two integrated evaluation items; then the fuzzy number is input into the fuzzy paired comparison matrix. Through the FAHP, the opinions of the decision maker are converted into the fuzzy number and membership function. Through the method of substituting a triangular fuzzy number into the paired comparison matrix, the opinions of all people are converted into a fuzzy positive reciprocal matrix to solve the problem of inaccuracy [31]. The FAHP consists of the following steps.

Step 1 (build up the fuzzy pairwise comparison matrix $\widetilde{A}$ ). Based on the fuzzy number $a_{i j}$ by a pair of evaluation items, we can build up the fuzzy pairwise comparison matrix. When $i$ is not equal to $1, \widetilde{a}_{i j}$ is equal to $\widetilde{a}_{i j}{ }^{-1}$. When $i$ is equal to $j, \widetilde{a}_{i j}$ is equal to $(1,1,1)$.

$$
\widetilde{A}=\left[\widetilde{a}_{i j}\right] ; \quad i=1,2 \ldots, n, j=1,2, \ldots, n
$$

Step 2 (calculate the fuzzy weight vector $\widetilde{W}$ ). Because the fuzzy positive reciprocal matrix is an irreducible matrix with positive values, the standardized relative weight values of each criterion can be calculated with a standardization process. The research adopts the column vector geometric mean.

$$
\begin{aligned}
Z_{i} & =\left(\mathrm{a}_{i 1} \otimes \mathrm{a}_{i 2} \otimes \ldots \otimes \mathrm{a}_{i n}\right)^{1 / n} \\
W_{i} & =\mathrm{Z}_{\mathrm{i}} \oslash\left(Z_{1} \oplus Z_{2} \oplus \ldots \oplus \mathrm{Z}_{\mathrm{n}}\right) \\
\widetilde{W} & =\left(W_{L}, W_{M}, W_{U}\right) ; \quad i=1,2, \ldots n
\end{aligned}
$$



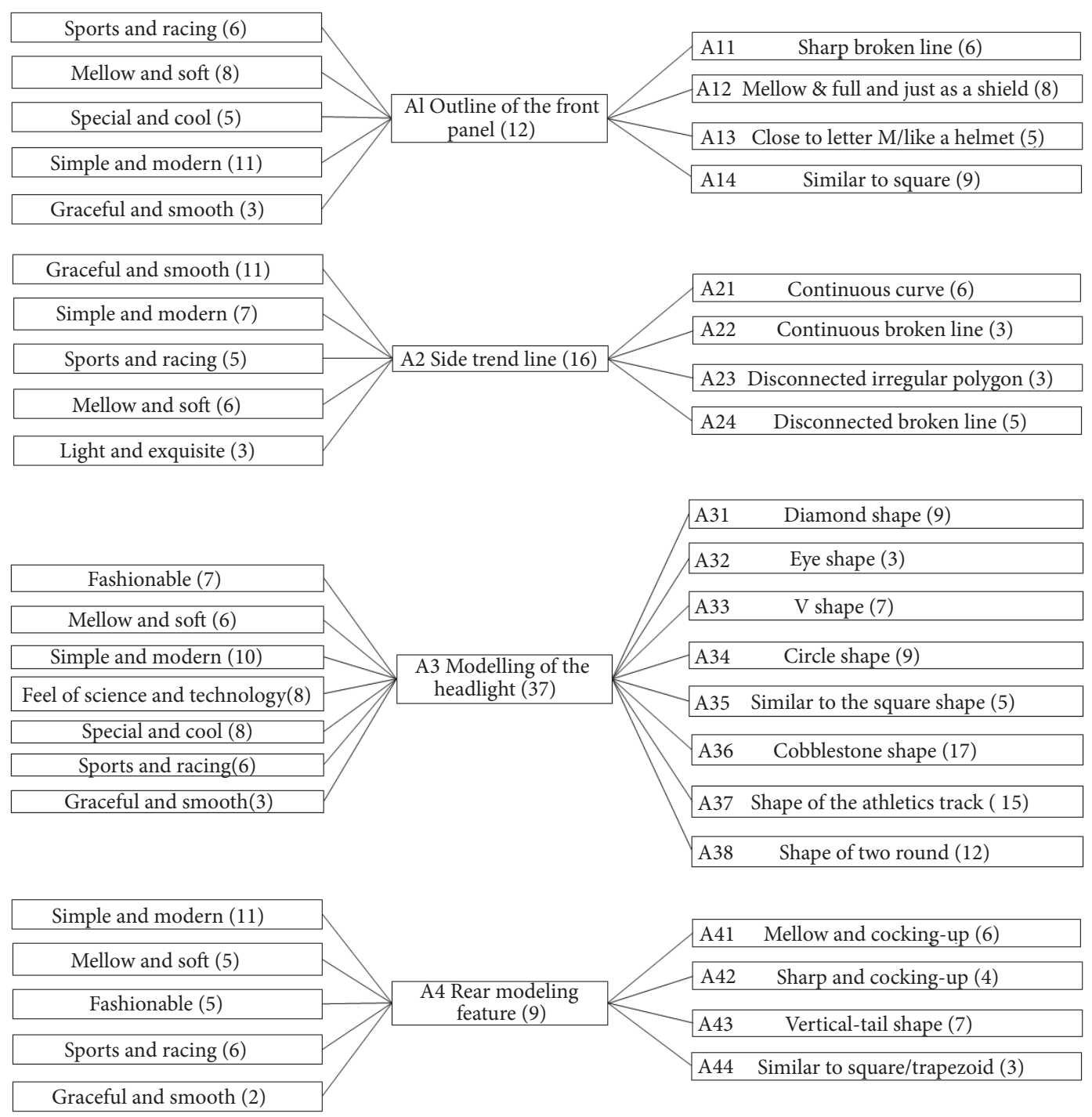

FIGURE 1: The hierarchical diagram of preferences by the EGM.

Step 3 (calculate the fuzzy maximum eigenvalue $\tilde{\lambda}_{\text {max }}$ ). The fuzzy maximum eigenvalue $\tilde{\lambda}_{\max }$ of the fuzzy pairwise comparison matrix $\widetilde{A}$ can be calculated as

$$
\widetilde{A} \widetilde{W}=\widetilde{\lambda}_{\max } \widetilde{W}
$$

The fuzzy maximum eigenvalue $\widetilde{\lambda}_{\max }$ of the fuzzy pairwise comparison matrix can also be defined in terms of triangular fuzzy numbers:

$$
\tilde{\lambda}_{\max }=\left(\lambda_{L \max }^{0}, \lambda_{M \max }^{1}, \lambda_{U \max }^{0}\right)
$$

where $\lambda_{L \text { max }}^{0}$ is the maximum eigenvalue of matrix $\lambda_{L}$, which refers to value on the left of the integrated expert fuzzy evaluation values; $\lambda_{M \max }^{1}$ is the maximum eigenvalue of matrix $\lambda_{M}$, which refers to the value in the middle of the integrated expert fuzzy evaluation values; and $\lambda_{U \text { max }}^{0}$ is the maximum eigenvalue of matrix $\lambda_{U}$, which refers to value on the right of integrated expert fuzzy evaluation values.
Step 4 (consistency verification). A consistency index (C.I.) is defined to confirm the rationality of the comparative matrix of the subject's reply result. It is recommended by Saaty [32] that C.I. $\leq 0.1$ is acceptable error and the maximum permissible range is C.I. $\leq 0.2$; the formula is as follows:

$$
\text { C.I. }=\frac{\lambda \max -n}{n-1},
$$

$n$ : number of the evaluation factors

where $\lambda \max$ is the maximum eigenvalue of the comparison matrix. If closer to $n$ (the number of elements in the matrix), it has more consistence. The ratio of the values of C.I. and a random index (R.I.) under the same matrix order is called the consistency ratio (C.R.):

$$
\text { C.R. }=\frac{\text { C.I. }}{\text { R.I. }}
$$


If C.R. is less than or equal to 0.1, the assessed values of the matrix have consistence; and every comparison matrix can correspond to the R.I. according to the number of elements, that is, the order $n$, as shown in Table 2 .

Step 5. This study is the comparison convenient for the final evaluation value. A simple center-of-gravity method is applied to convert the fuzzy weight of each initial criterion $\widetilde{W}_{i}$ into a single value $D F_{i}$, and its calculation method is as follows:

$$
D F_{i}=\frac{\left[\left(W_{U i}-W_{L i}\right)+\left(W_{M i}-W_{L i}\right)\right]}{3}+W_{L i}
$$

where $D F_{i}$ is the defuzzification value; $\widetilde{W_{i}}$ is the $i$ th fuzzy weight vector; $W_{U i}$ is the maximum value of the triangle fuzzy number of the $i$ th fuzzy weight vector; $W_{M i}$ is the median of the triangle fuzzy number of the $i$ th fuzzy weight vector; and $W_{L i}$ is the lowest value of the triangle fuzzy number of the $i$ th fuzzy weight vector.

\subsubsection{Calculation of the Kansei Image's Satisfaction Evaluation} Index via the C-FKM. The C-FKM is based on the theories of the Kano model and the FKM, which integrates the fuzzy skills and the quantitative analysis method of the Kano model [14]. Wu and Wang [14] defined a continuous approach to the FKM evaluations as follows.

Step 1. The two-way questionnaire is conducted to consumers participating in the survey. The question pair included a functional question capturing a consumer's perception, namely, the product possessed a certain attribute and a nonfunctional question capturing a consumer's perception; namely, the product did not possess the attribute. In the questionnaire, a participant only needed to select a standpoint as his or her answer to the question, as shown in Table 3 [14].

The preference of the $n$th consumer can be expressed by the following formula:

$$
u_{n i j}=\mathrm{m}\left(\mathrm{F}_{\mathrm{i}}\right)_{n} \times \mathrm{m}\left(\mathrm{D}_{j}\right)_{n}
$$

where the two $n$ subscripts denote the participants; the first one denotes the membership of the ith standard answer, containing the functional questions; the second one denotes the membership of the $j$ th standard answer, containing the dysfunctional questions.

Based on the calculation results of the two answers via (16) and with reference to the Kano evaluation table (Table 1) [16], the membership degree $\left(u_{n i j}\right)$ of the $N$ th consumer's preference can be identified as the following five levels, namely, "attractive," "Must-Be," "one-dimensional," "indifferent," or "reverse."

Step 2. The individual satisfaction $\left(S_{n}\right)$ can be obtained via a mathematical aggregation of the influence values, which are weighted by the following formula:

$$
S_{n}=\sum_{i=1}^{5} \sum_{j=1}^{5} v_{i j} \times u_{n i j}
$$

According to Table 4, different values may be given to the 25 combinations in the Kano evaluation table. An influence value is introduced to describe the contribution of each combination to consumer satisfaction. As shown in Table 1, the qualities of "Must-Be," "one-dimensional," and "attractive" were 2,1 , and 0.5 , respectively [15]. In the upper-right quadrant of Table 4, the influence values decrease counterclockwise. The presentation of the lower left quarter was the reverse of the presentation of the top right quarter [16].

The value of influence can be divided according to its maximum value; thus, a standard matrix of the influence value can be obtained, as shown in the following formula:

$$
\begin{aligned}
\text { NIV } & =\left(v_{i j}\right)_{5 \times 5} \\
& =\left[\begin{array}{ccccc}
0 & 0.200 & 0.250 & 0.300 & 0.500 \\
-0.100 & 0 & 0.050 & 0.075 & 0.900 \\
-0.125 & -0.250 & 0 & 0.100 & 1.000 \\
-0.150 & -0.038 & -0.050 & 0 & 0.800 \\
-0.250 & -0.450 & -0.500 & -0.400 & 0
\end{array}\right]
\end{aligned}
$$

Step 3. The values of $S_{n}$ required by every participant may be evaluated according to the different importance values given by the participants. The importance of preference degree on the Kansei image differed from each consumer's demand. Therefore, the participants were able to select a number from 1 to 9 as the score of the importance of each specific consumer demand in the questionnaire design.

The average of the total participant satisfaction for a specific consumer's demand is expressed by the evaluation indicator (EI), which was employed to represent the average evaluation of all participants. Given $N$ participants, the value of EI can be calculated by using the following formula:

$$
E I=\frac{\sum_{n=1}^{N} w_{n} S_{n}}{N}
$$

2.2.3. Adjustment of Final Weights. The SAM and FAHP are used to obtain the weights of the criteria. By multiplying with the adjustment coefficient $(\mathrm{K})$, for each Kano category, the weights of the criteria are regulated. It is recommended by Chen and Chuang [33] that the criteria in the attractive category should be concerned firstly, and, then, lower priorities should be given to the criteria in the one-dimensional and Must-Be categories successively. Furthermore, the adjustment coefficient $(\mathrm{K})$ set by Chen and Chuang is as follows: the "attractive" category is set as preference 4, "one-dimensional" as 2, "Must-Be" as 1, and "indifferent" as 0 [33]. However, there exists a deficiency; namely, the FKM is still a qualitative method without considering the discontinuity problem [14], resulting in inaccurate judgement on the quality attribute of the criterion. Accordingly, the corresponding adjustment coefficient is also incorrect. Therefore, in this study, the weight adjustment method based on the C-FKM classification is proposed to reprioritize the criteria. The Kansei image weight adjustment can be expressed as [33] 
TABLE 2: Random index.

\begin{tabular}{|c|c|c|c|c|c|c|c|c|c|c|c|c|c|c|c|}
\hline $\mathrm{n}$ & 1 & 2 & 3 & 4 & 5 & 6 & 7 & 8 & 9 & 10 & 11 & 12 & 13 & 14 & 15 \\
\hline RI & 0 & 0 & 0.58 & 0.90 & 1.12 & 1.24 & 1.32 & 1.41 & 1.45 & 1.49 & 1.51 & 1.48 & 1.56 & 1.57 & 1.59 \\
\hline
\end{tabular}

TABLE 3: Continuous fuzzy Kano questionnaire table.

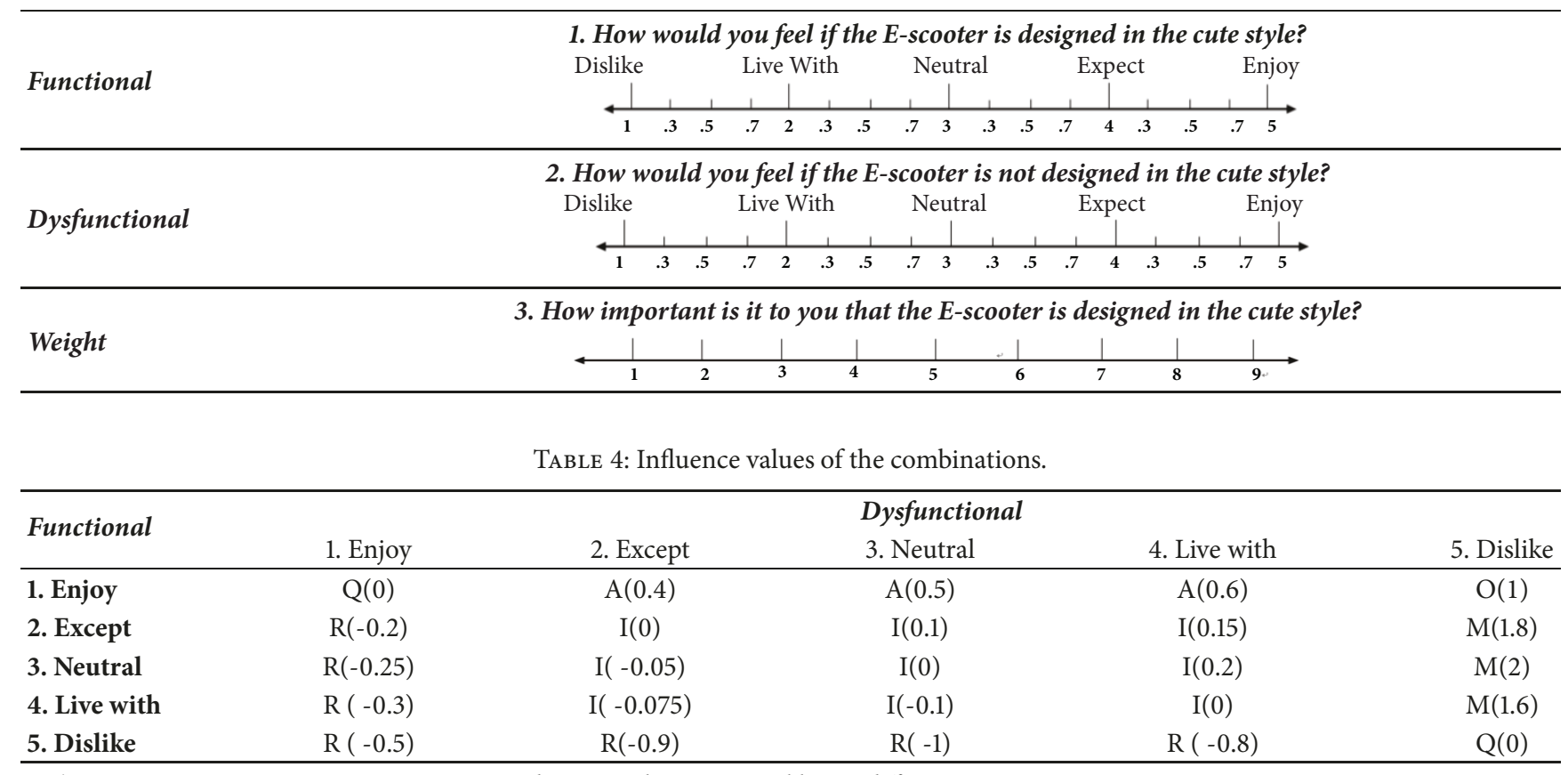

Node: A: attractive; M: Must-Be; R: reverse. O: one-dimensional; Q: questionable; I: indifferent.

$$
w_{i \_a d j}=\frac{W_{i} K_{i}}{\sum_{i=1}^{n} W_{i} K_{i}}
$$

where $w_{i_{-} \text {adj }}$ is the weight value adjusted for the $i$ th element; $w_{i}$ is the Kansei image weight of the $i$ th element, $\mathrm{i}=1,2, \ldots, n$; and $K_{i}$ is the adjustment coefficient according to continuous fuzzy Kano quality classification. The Kansei image priority is determined using the weight adjustment method.

2.3. Test Stage. This study was directed at consumer demand, and the expression of the consumer perpetual demand was realized for the product image dimension. In the fuzzy computing stage of the study, we selected eight Kansei words to express the images of the consumer for the product and obtained the Kansei words that affected consumer preference using the C-FKM and FAHP. In the test stage, we verified the reliability of these attractive qualities depending on the Kansei images experiment.

In this study, 22 samples of an electric scooter were selected to test the preferences of the testees for the front face based on a five-point Likert scale. As shown in Table 5, the measuring scale of the questionnaire consisted of the feelings "strongly dislike," "dislike," "neutral," "like," and "strongly like"; their corresponding scores were 1, 2, 3, 4, and 5 , respectively. By calculating the mean of the scores of all testees, we can select the top five most preferred electric scooters among the 22 specimens.
The testees were invited to conduct a perceptual evaluation of the electric scooter specimens, of which the degree of preference was ranked for the top five according to the individual feelings of the testees. As shown in Table 6, the questionnaire was a five-point Likert scale that listed scores from 1 to 5, which corresponded to positions from left to right. A value of 1 indicates that the sample deviated from the feeling expressed by this Kansei word, a value of 3 represents the feeling of neutrality, and a value of 5 indicates that the sample reflects the feeling expressed by this Kansei word.

2.4. Quantitative Analysis Stage. In product design, quantification theory type I (QTT-I) [34] can be used to evaluate the weight of factors that stem from consumers' preferences [35]. In the quantitative analysis stage, we conducted the analysis of QTT-I to determine the important modeling features that affect the Kansei words and employed them as a reference upon which the modeling design preferred by the consumer can be enhanced.

QTT-I is used to establish the functional relation between a group of qualitative variables (independent variables) and a group of quantitative variables (dependent variables) according to the results of the fuzzy computing stage. Next, we distinguished the words with attractive qualities from the eight Kansei words. Then, we employed the evaluated values of the Kansei words as the dependent variable and converted the modeling features in Table 7 to the independent 
TABLE 5: List of scores for the preference of a testee for the samples according to a Likert scale.

\begin{tabular}{lccccc}
\hline Sample & \multicolumn{5}{c}{ Scale } \\
\hline$p$ & 1 & 2 & 3 & 4 & 5 \\
& $\begin{array}{c}\text { Strongly } \\
\text { dislike }\end{array}$ & Dislike & Neutral & Like & Strongly like \\
\hline
\end{tabular}

TABLE 6: List of scores for the testee to describe the image of the sample according to a Likert scale.

\begin{tabular}{|c|c|c|c|c|c|c|}
\hline \multirow{2}{*}{ Sample } & \multirow{2}{*}{$\begin{array}{c}\text { Kansei Word } \\
\text { Simple and modern }\end{array}$} & \multicolumn{5}{|c|}{ Scale } \\
\hline & & 1 & 2 & 3 & 4 & 5 \\
\hline & Special and cool & 1 & 2 & 3 & 4 & 5 \\
\hline & Mellow and soft & 1 & 2 & 3 & 4 & 5 \\
\hline & Fashionable & 1 & 2 & 3 & 4 & 5 \\
\hline & $\ldots \ldots \ldots$ & $\ldots$ & $\ldots$ & $\ldots$ & $\ldots$ & \\
\hline
\end{tabular}

variable. We can use 0 or 1 to determine whether the sample corresponds to the item and certain feature categories of the items listed in Table 7. If a sample possesses this feature, it is marked as 1; if the sample does not possess this feature, it is marked as 0 . All results of the survey are input into the matrix. By performing a multivariate regression analysis, a mathematical model for the variables is established, and the prediction of the independent variable can be realized. A QTT-I calculation tool was used for the analysis.

\section{Results}

3.1. Using the C-FKM and FAHP to Investigate the Priority of Kansei Images. Kansei words were compared in pairs using the SAM. The evaluation values of 20 experts on a group of compared Kansei words were aggregated to obtain the opinion $A M$ (Table 8). Equations (1)-(3) were used to calculate the mean agreement degree $\mathrm{A}(\mathrm{Ek})$ of each expert on the overall evaluation values. Equation (4) was used to calculate the $R A D$ of expert opinions.

The calculated $R A D$ of expert opinions was used as the weight and was combined with the expert opinion triangle fuzzy values to calculate the fuzzy evaluation values of experts on a group of Kansei words according to (5) and (6), as shown in Table 9.

The above steps were repeated for other Kansei words. The consensus opinions of experts were aggregated and a fuzzy paired comparison matrix for all descriptive words for the electric scooter was obtained. An FAHP was conducted to obtain the opinions of all experts according to (7)-(15). The evaluation values for all Kansei words are listed in Tables 10 and 11.

According to the consistency verification method proposed by Saaty [32], C.I. $\leq 0.1$ is an acceptable error, C.I. $\leq 0.2$ is the maximum allowable range, and C.R. $\leq 0.1$ suggests that the matrix evaluation values are consistent. In this example, the maximum fuzzy eigenvalue is $\lambda_{\max }=8.5543$, C.I. $=0.0792$, and $C . R .=0.0562$, indicating that the results are all within a reasonable range.

Table 12 provides the C-FKM analysis of the results. The C-FKM analysis integrated the fuzzy theory and the quantitative analysis into the Kano model [14]. The C-FKM analysis was established based on the starting value of the EI. When the value of the EI was greater than or equal to zero (e.g., EI $\geq 0.1$ ), the perceptual demands of the user could be satisfied. When the value of EI was greater than or equal to 0.1, the Kansei images "fashionable," "simple and modern," "special and cool," "graceful and smooth," and with a feeling of "science and technology" were classified as attractive demands according to the C-FKM analysis (see Table 12). This classification is equivalent to the FKM classification. Based on the C-FKM analysis, we deduced that the EI value of the Kansei image "light and exquisite" was 0.1207. Since this EI value was greater than 0.1, "light and exquisite" was classified as an attractive image. Although the EI value was greater than 0.1, the value is low; thus, the Kansei image "light and exquisite" was classified as having insignificant attractive qualities. When the EI was less than 0.1, the Kansei images "sports and racing" and "mellow and soft" were classified as words with indifferent qualities according to the C-FKM, as shown in Table 12.

With the help of (20), we obtain Adjusted1, which corresponds to the weights and adjustment coefficient of the eight Kansei images, as shown in Table 12. Adjusted1 has the following shortcoming. The consumer demand with the same quality category has the same adjustment coefficient; for example, in the case study, the "simple and modern," "graceful and smooth," "fashionable and novel," "special and cool," "science and technology," and "light and exquisite" quality categories belong to the "attractive" C-FKM category. According to the adjustment coefficient $(K)$ set by Chen [30], all adjustment coefficients are 4 , which ignores the difference of the satisfaction coefficient between the consumer demand items with the same quality attributes [14]. In this study, the EI value of the C-FKM model multiplied by the weight value (Adjusted2) is applied to determine the priority of Kansei images.

3.2. Comparison of the Results of the Perceptual Evaluative Experiment and the Priority of Adjusted Weights/C-FKM Quality Classification. In this stage, we established a semantic difference (SD) scale according to the semantic differential 
TABLE 7: Kansei valuation matrix.

\begin{tabular}{|c|c|c|c|c|c|c|c|c|c|c|c|c|c|c|}
\hline \multirow[t]{3}{*}{ No. } & \multirow[t]{3}{*}{ Sample } & \multicolumn{12}{|c|}{ Modeling features } & \multirow{3}{*}{$\begin{array}{l}\text { Evaluation value } \\
\text { Simple and modern }\end{array}$} \\
\hline & & \multicolumn{3}{|c|}{$\mathrm{A} 1$} & \multicolumn{3}{|c|}{$\mathrm{A} 2$} & \multicolumn{3}{|c|}{ A3 } & \multicolumn{3}{|c|}{ A4 } & \\
\hline & & $\mathrm{A}_{11}$ & $\ldots$ & $\mathrm{A}_{14}$ & $\mathrm{~A}_{21}$ & $\ldots$ & $\mathrm{A}_{24}$ & $\mathrm{~A}_{31}$ & $\ldots$ & $\mathrm{A}_{38}$ & $\mathrm{~A}_{41}$ & $\ldots$ & $\mathrm{A}_{44}$ & \\
\hline 1 & $\bar{P} \times \frac{1}{9}$ & 0 & $\ldots$ & 0 & 1 & 0 & 0 & 0 & $\ldots$ & 0 & 1 & 0 & 0 & 4.5385 \\
\hline$\vdots$ & $\vdots$ & $\vdots$ & $\vdots$ & $\vdots$ & $\vdots$ & $\vdots$ & $\vdots$ & $\vdots$ & $\vdots$ & $\vdots$ & & & & $\vdots$ \\
\hline 22 & शु. & 0 & $\cdots$ & 1 & 0 & $\ldots$ & 1 & 0 & $\cdots$ & 0 & 0 & $\ldots$ & 1 & 3.8846 \\
\hline
\end{tabular}

TABLE 8: Recognition matrix of experts for a pair of Kansei words.

\begin{tabular}{lcccccccccccccc}
\hline & E1 & E2 & E3 & E4 & E5 & $\ldots$ & E15 & E16 & E17 & E18 & E19 & E20 & $\boldsymbol{A ( \boldsymbol { E } _ { \boldsymbol { k } } )}$ & $\boldsymbol{R} \boldsymbol{A D}(\boldsymbol{W i})$ \\
\hline E1 & 1 & 0 & 0 & 0 & 0 & $\ldots$ & 0 & 0 & 0 & 0 & 0.1429 & 0 & 0.0159 & 0.0033 \\
E2 & 0 & 1 & 0 & 1 & 0 & $\ldots$ & 0.1304 & 0 & 0 & 0 & 0 & 0 & 0.3027 & 0.0631 \\
$\vdots$ & $\vdots$ & $\vdots$ & $\vdots$ & $\vdots$ & $\vdots$ & $\vdots$ & $\vdots$ & $\vdots$ & $\vdots$ & $\vdots$ & $\vdots$ & $\vdots$ & \\
E19 & 0.1429 & 0 & 0 & 0 & 0.1429 & $\ldots$ & 0 & 0.1429 & 0 & 0.1429 & 1 & 0 & 0.0953 & 0.0198 \\
E20 & 0 & 1 & 0 & 1 & 0 & $\ldots$ & 0.1304 & 0 & 0 & 0 & 0 & 1 & 0.3027 & 0.0631 \\
\hline
\end{tabular}

TABLE 9: Expert consensus on comparing a pair of Kansei words.

\begin{tabular}{lccccccc}
\hline & $\boldsymbol{W}_{\boldsymbol{i}}$ & $\boldsymbol{L}_{\boldsymbol{i}}$ & $\boldsymbol{W}_{\boldsymbol{i}} * \boldsymbol{L}_{\boldsymbol{i}}$ & $\boldsymbol{M}_{\boldsymbol{i}}$ & $\boldsymbol{W}_{\boldsymbol{i}} * \boldsymbol{M}_{\boldsymbol{i}}$ & $\boldsymbol{U}_{\boldsymbol{i}}$ & $\boldsymbol{W}_{\boldsymbol{i}} * \boldsymbol{U}_{\boldsymbol{i}}$ \\
\hline E1 & 0.0033 & 6 & 0.0198 & 7 & 0.0232 & 0.0265 \\
E2 & 0.0631 & $1 / 2$ & 0.0315 & $\vdots$ & 1 & 0.0631 & 0.1261 \\
$\vdots$ & $\vdots$ & $\vdots$ & 3 & 0.0992 & 6 & $\vdots$ & $\vdots$ \\
E19 & 0.0198 & $1 / 2$ & 0.0315 & 1 & 0.1191 & $\vdots$ & 7 \\
E20 & 0.0631 & & 2.3885 & & 3.1555 & 0.1389 \\
& & & & & & 0.1261 \\
\hline
\end{tabular}

TABLE 10: Fuzzy pairwise comparison matrix of Kansei words.

\begin{tabular}{|c|c|c|c|c|c|c|c|c|c|c|c|}
\hline Kansei & $K w 1$ & $K w 2$ & $K w 3$ & $K w 4$ & $K w 5$ & $K w 6$ & $K w 7$ & $K w 8$ & Weights & $A W$ & $\lambda$ \\
\hline$K w 1$ & 1.0000 & 3.1555 & 1.8844 & 3.0914 & 2.7430 & 2.5198 & 4.3350 & 5.2900 & 0.2797 & 2.3926 & 8.5542 \\
\hline$K w 2$ & 0.3169 & 1.0000 & 1.2337 & 1.7843 & 1.4980 & 2.7134 & 3.2159 & 3.0324 & 0.1563 & 1.3171 & 8.4292 \\
\hline$K w 3$ & 0.5307 & 0.8106 & 1.0000 & 1.2965 & 1.2473 & 1.6348 & 2.9218 & 3.1375 & 0.1383 & 1.1210 & 8.1041 \\
\hline$K w 4$ & 0.3235 & 0.5604 & 0.7713 & 1.0000 & 2.4206 & 3.1018 & 3.6036 & 3.8009 & 0.1440 & 1.2630 & 8.7711 \\
\hline$K w 5$ & 0.3646 & 0.6676 & 0.8017 & 0.4131 & 1.0000 & 3.7120 & 3.8450 & 4.3511 & 0.1262 & 1.1077 & 8.7774 \\
\hline$K w 6$ & 0.3969 & 0.3685 & 0.6117 & 0.3224 & 0.2694 & 1.0000 & 2.7845 & 4.1276 & 0.0763 & 0.6757 & 8.8567 \\
\hline$K w 7$ & 0.2307 & 0.3110 & 0.3423 & 0.2775 & 0.2601 & 0.3591 & 1.0000 & 2.2701 & 0.0456 & 0.3826 & 8.3976 \\
\hline$K w 8$ & 0.1890 & 0.3298 & 0.3187 & 0.2631 & 0.2298 & 0.2423 & 0.4405 & 1.0000 & 0.0337 & 0.2876 & 8.5439 \\
\hline
\end{tabular}

Note: $K w$ : Kansei word; $A W$ : multiply the comparison matrix $A$ and weights. $\lambda \mathrm{Max}=8.5543 ; \mathrm{CI}=0.0792 ; \mathrm{CR}=0.0562$.

TABLE 11: Priority weights in the FAHP.

\begin{tabular}{|c|c|c|c|c|c|c|}
\hline Criteria & Kansei word & & betwee & $\%)$ & Defuzzification & Priorities \\
\hline$K w 1$ & Simple and modern & 0.2282 & 0.2797 & 0.3209 & 0.2762 & 1 \\
\hline$K w 2$ & Graceful and smooth & 0.1320 & 0.1563 & 0.1767 & 0.1550 & 2 \\
\hline$K w 3$ & Fashionable & 0.1322 & 0.1383 & 0.1395 & 0.1367 & 4 \\
\hline$K w 4$ & Special and cool & 0.1509 & 0.1440 & 0.1341 & 0.1430 & 3 \\
\hline$K w 5$ & Feel of science and technology & 0.1516 & 0.1262 & 0.1059 & 0.1279 & 5 \\
\hline$K w 6$ & Light and exquisite & 0.0974 & 0.0763 & 0.0618 & 0.0785 & 6 \\
\hline$K w 7$ & Mellow and soft & 0.0607 & 0.0456 & 0.0358 & 0.0474 & 7 \\
\hline$K w 8$ & Sports and racing & 0.0470 & 0.0337 & 0.0253 & 0.0353 & 8 \\
\hline
\end{tabular}


TABLE 12: Attribute priorities of Kansei images.

\begin{tabular}{|c|c|c|c|c|c|c|c|c|}
\hline \multirow{2}{*}{ Kansei image } & \multicolumn{3}{|c|}{ C-FKM } & \multirow{2}{*}{$\begin{array}{c}\text { FAHP } \\
W_{i}\end{array}$} & \multirow{2}{*}{$\begin{array}{c}\text { Adjusted1 } \\
W_{i} * K\end{array}$} & \multirow{2}{*}{$\begin{array}{c}\text { Adjusted2 } \\
W_{i} * E_{i}\end{array}$} & \multirow{2}{*}{$\begin{array}{c}\text { Adjusted2 } \\
\text { Normalized }\end{array}$} & \multirow{2}{*}{ Priorities } \\
\hline & $E_{i}$ & Category & K & & & & & \\
\hline Simple and modern & 0.2204 & Attractive & 4 & 0.2762 & 1.1048 & 0.0609 & 0.3593 & 1 \\
\hline Graceful and smooth & 0.1659 & Attractive & 4 & 0.1550 & 0.6200 & 0.0257 & 0.1518 & 2 \\
\hline Fashionable & 0.1604 & Attractive & 4 & 0.1367 & 0.5468 & 0.0219 & 0.1294 & 4 \\
\hline Special and cool & 0.1682 & Attractive & 4 & 0.1430 & 0.5720 & 0.0241 & 0.1420 & 3 \\
\hline Science and technology & 0.1645 & Attractive & 4 & 0.1279 & 0.5116 & 0.0210 & 0.1242 & 5 \\
\hline Light and exquisite & 0.1207 & Attractive & 4 & 0.0785 & 0.3140 & 0.0095 & 0.0559 & 6 \\
\hline Mellow and soft & 0.0945 & Indifferent & 0 & 0.0474 & 0.0000 & 0.0045 & 0.0264 & 7 \\
\hline Sports and racing & 0.0527 & Indifferent & 0 & 0.0353 & 0.0000 & 0.0019 & 0.0110 & 8 \\
\hline
\end{tabular}

Note: $E_{i}$ : mean of the satisfaction of all participants for the demands of a specific consumer. $W_{i}$ : weight; $K$ : adjustment coefficient.

TABLE 13: Kansei words whose mean ranks in the top four.

\begin{tabular}{lcc}
\hline Sample 18 & Kansei image & Mean of SD \\
\hline & Fashionable & 3.7692 \\
& Special and cool & 3.2308 \\
& Feel of science and technology & 3.6538 \\
& Simple and modern & 3.9231 \\
\hline
\end{tabular}

method to conduct the specimen perceptual evaluation experiment. By calculating the means for all testees, we selected the electric scooter for which the testee preference ranked in the top five among the 22 samples. By combining the selected eight Kansei images in the early experiment stage with the top five electric scooter samples preferred by the testees, we established a five-point Likert scale and scored according to the scores $1,2,3,4$, and 5 . After calculating the means of all testees, the Kansei images that ranked in the top four were obtained and were used to describe the perceptual image for the appearance modeling of the sample. For example, for sample 5, the Kansei images that ranked in the top four were "fashionable," "shapely," "feel of science and technology," and "simple and generous," of which the means were $3.7692,3.2308,3.6538$, and 3.9231, respectively. Thus, we use these top four Kansei images to describe the modeling images of sample 5, as shown in Table 13.

The experimental results of the top five among the 22 samples preferred by consumers were compared with the results of the priority of adjusted weights. The results are shown in Table 14.

3.3. Data Analysis by QTT-I. The main reasons why customers prefer an electric scooter as well as the weight relationship between the Kansei images and the modeling features were calculated by QTT-I.

\section{Discussion and Analysis}

In the early stage of product development, the designers can integrate the high-ranking Kansei images into their design according to the priority of adjusted weights. As shown in Table 12, according to the results of the C-FKM classification, six attractive quality items-among them, the attractive qualities of "fashionable," "simple and modern," "feel of science and technology," "graceful and smooth," and "special and cool"-yielded a high value, whereas the other attractive qualities yielded a low value. Thus, in the model design of an electric scooter, the high-ranking Kansei images are regarded as the first choice by designers.

The result obtained from the C-FKM is the quality attribute classification of the Kansei images based on the consumers' satisfaction, while the result calculated from the FAHP is the rank ordering the importance degree of the Kansei images. It is recommended by Chen [33] that the criteria in the attractive category should be concerned with, firstly, "simple and modern," "special and cool," and "graceful and smooth." The adjustment coefficient $(\mathrm{K})$ set is as follows [33]. The attractive category is set as preference 4, indifferent category 0 . Table 12 provides the C-FKM analysis of the results; the "simple and modern," "graceful and smooth," "fashionable and novel," "special and cool," "science and technology," and "light and exquisite" quality categories belong to the "attractive" category, and all adjustment coefficients are 4 , which ignores the difference of the satisfaction coefficient between the consumer demand items with the same quality attributes [14]. Wu and Wang developed a C-FKM based on the ranking of the satisfaction EI value, which can help identify the degree of contribution of product satisfaction to promoting product design. Therefore, the adjustment method based on EI value and weight value (Adjusted2) is used for the priority of Kansei images, as shown in Table 12.

The procedure is to carry out the perceptual evaluative experiment to 22 samples and then test the Kansei image composition of the samples whose consumer preference is ranked in the top five to obtain four Kansei images of the five samples with the highest average score. The results are 


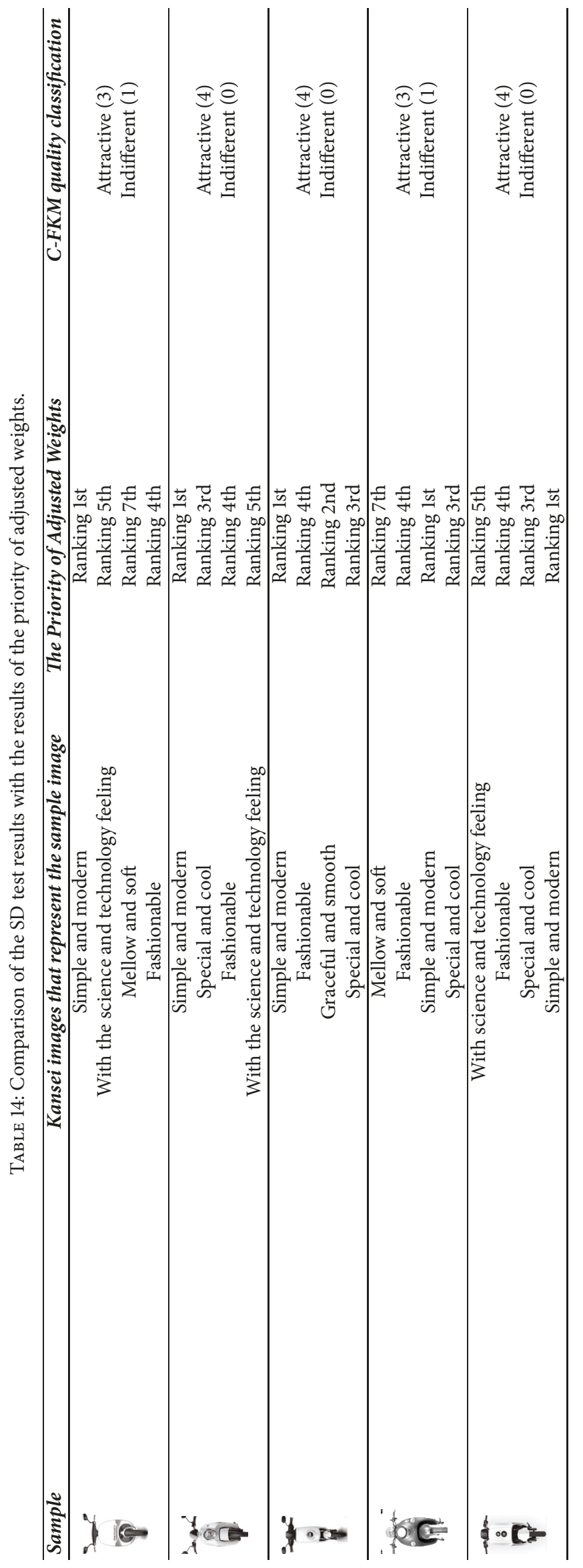


TABLE 15: QTT-I Results for “simple and modern.”

\begin{tabular}{|c|c|c|c|}
\hline Item & Attractive factor & $C S^{a}$ & $P C C^{b}$ \\
\hline \multirow{4}{*}{ Al Outline of the front panel } & All Sharp broken line & -0.8072 & \multirow{4}{*}{0.8986} \\
\hline & A12 Mellow \& full and just as a shield & 0.3579 & \\
\hline & A13 Close to letter M/like a helmet & -1.5130 & \\
\hline & A14 Similar to square & 0.3648 & \\
\hline \multirow{4}{*}{ A2 Side trend line } & A21 Continuous curve & 0.9360 & \multirow{4}{*}{0.8615} \\
\hline & A22 Continuous broken line & -0.0211 & \\
\hline & A23 Disconnected irregular polygon & 0.1643 & \\
\hline & A23 Disconnected broken line & -0.8649 & \\
\hline \multirow{8}{*}{ A3 Modelling of the headlight } & A31 Diamond shape & 0.9353 & \multirow{8}{*}{0.6660} \\
\hline & A32 Eye shape & 0.0256 & \\
\hline & A33 V-shape & 0.2564 & \\
\hline & A34 Circle shape & -0.0898 & \\
\hline & A35 Similar to the square shape & -0.3784 & \\
\hline & A36 Cobblestone shape & 0.0231 & \\
\hline & A37 Shape of the athletics track & -0.1204 & \\
\hline & A38 Shape of two round & -0.2683 & \\
\hline \multirow{4}{*}{ A4 Rear modeling features } & A41 Mellow and cocking-up & -0.3544 & \multirow{4}{*}{0.7772} \\
\hline & A42 Sharp and cocking-up & 0.4509 & \\
\hline & A43 Vertical-tail shape & -0.8116 & \\
\hline & A44 Similar to square/trapezoid & 0.5208 & \\
\hline \multirow[t]{3}{*}{ Constant } & & 3.3338 & \\
\hline & $\mathrm{R}=0.9220$ & & \\
\hline & $\mathrm{R} 2=0.8501$ & & \\
\hline
\end{tabular}

Notes: ${ }^{a}$ category scores. ${ }^{b}$ Partial correlation coefficients. R: multiple correlation; $\mathrm{R}^{2}$ : determination coefficient.

shown in Table 14. For example, for sample 5, which was the preferred sample by the testers, the classification results in Table 12 indicate that the four Kansei images "fashionable," "special and cool," "feeling of science and technology," and "simple and modern" are classified as Kansei images with attractive qualities. The final adjustment weight is ranking 1 st, ranking 3rd, ranking 4th, and ranking 5th. As shown in Table 14 and according to the results of the C-FKM classification, among the top five samples preferred by consumers, each sample contained at least three Kansei images with attractive qualities. According to the results of the priority of adjusted weights, among the top five samples preferred by consumers, each sample contained at least two Kansei images with higher rankings. The comparison of the experimental results in the results of the priority of adjusted weights/CFKM quality classification verifying that, for the sample with high preference, the weight of its Kansei images ranks ahead and is also associated with the Kansei images of the obtained attractive qualities to some extent. In other words, in the model design of an electric scooter, the high-ranking Kansei images are regarded as first choice by designers to arouse the attention of consumers.

Using the evaluation scores for the 22 samples with regard to the Kansei image "simple and modern" as the dependent variable and the modeling parameters of the tested samples as the independent variable, we conducted an analysis according to QTT-I to obtain the important modeling features that impact the Kansei image. We employed these features as the gist on which the modeling design improves the qualities and enhances user preference. An example of the results of the analysis according to QTT-I was the Kansei image "simple and modern." With regard to the e-scooter, the features of the headlight shape, outline of the front panel, rear modeling features, and side trend line produced a "simple and modern" feeling for the testee. According to Table 15, the partial correlation coefficients of the outline of the front panel and side trend line were 0.8986 and 0.8615 , respectively, and both values exceeded 0.80 . Both factors caused the testees to feel stronger "simple and modern" feelings. The coefficient of determination, expressed as $\mathrm{R}^{2}$, was employed to interpret the ability of the modeling parameters to explain the dependent variable; $\mathrm{R}^{2}$ is between 0 and 1 , and the greater the value, the stronger the correlation. The coefficient of determination, $\mathrm{R}^{2}$, was 0.8501 , which indicated that this model had high precision. For example, in the model of the e-scooter, the modeling parameters A14 ("similar to square"), A12 ("mellow \& full and just as a shield"), and A21 ("continuous curve") were $0.3648,0.3579$, and 0.936 , respectively. The modeling of "similar to square," "mellow \& full and just as a shield," and "continuous curve" was able to produce strong simple and modern feelings for the testees.

\section{Conclusion}

In this study, we used an electric scooter as the research case. In the fuzzy computing, the author discovered that six Kansei 
words were classified as words with attractive qualities. In the test stage, the author selected electric scooter as the specimen and invited the subjects to participate in a perceptual evaluation experiment. Then, the author compared the research results of the two stages and discovered that the images of the electric scooter preferred by the testees comprised the attractive qualities. In quantitative analysis stage, to find the weight relationship between the Kansei images and the modeling features, we conducted an analysis according to QTT-I. The main conclusions of this paper are as follows. (1) It was difficult for the FKM to accurately define consumer demand when the data differences among two or more categories were small. In addition, the classification for the quality attributes of the Kansei images based on the C-FKM was more accurate. (2) In this study, the weight adjustment method based on the ranking of the satisfaction EI value was proposed. (3) The FAHP and SAM were applied to rank the importance degree of the Kansei image more accurately. (4) This was the first study of its kind to combine the C-FKM and FAHP to determine the priority of the Kansei images of the products. This study can help product developers to more accurately analyze consumers' Kansei needs and increase customer satisfaction from the product design process.

Since certain limitations still exist, this research needs to be continually improved. Because each Kansei word is concise, comprehensive, and unable to state the semantic space of the products, the evaluation of the quality categories of the Kansei words will contain errors. Because some sample brands were extremely popular in the electric scooter sample preference experiment, even if we removed information such as the product mark, some customers had a subjective tendency toward the brand in the test. In future research, specialized research can be conducted on products of a certain brand. By studying users' preferences of the brand's products, the attractive factors of users' preferences can be retained and can be continuously updated by reorganization or design variation, so as to help the enterprise effectively develop new products. In this study, the author did not conduct a comparative study on ethnic groups. The results of the study will change with different ethnic groups and other factors. Because different groups have different perceptions on product aesthetics, future research can be conducted on the Kansei images of different ethnic groups according to different gender, age, degree of education, occupation, economic income, and other factors.

\section{Data Availability}

The data used to support the findings of this study are available from the corresponding author upon request.

\section{Conflicts of Interest}

The authors declare that there are no conflicts of interest regarding the publication of this paper.

\section{Supplementary Materials}

The data relevant to this study are included in the Supplementary Material section. There are three documents, one of which is the EI value calculation performed by one of the authors using MATLAB and Excel; this file contains a description of the calculation process and is the source of the tables in this paper. Another document is a questionnaire survey of product developers and researchers conducted by one of the authors, using MATLAB to calculate and then establish a pair of matrices and then calculate the fuzzy weight value. The initial datasets for this series of calculations are included in the file. The third document is the QTT-I calculation; the researchers adopted the QTT-I calculation tool for the analysis. The paper's table contains the phased results. (Supplementary Materials)

\section{References}

[1] M. Nagamachi, "Kansei engineering: a new ergonomic consumer-oriented technology for product development," International Journal of Industrial Ergonomics, vol. 15, no. 1, pp. 3-11, 1995.

[2] N. Kano, F. Seraku, Takahashi, and S. Tsuji, "Attractive quality and must-be quality," Journal of The Japanese Society for Quality Control, vol. 14, no. 2, pp. 147-156, 1984.

[3] S. Nowak and S. Rüger, "How reliable are annotations via crowdsourcing? A study about inter-annotator agreement for multilabel image annotation," in Proceedings of the ACM SIGMM International Conference on Multimedia Information Retrieval (MIR '10), pp. 557-566, March 2010.

[4] S. Murai, K. Ono, and N. Tanaka, "Kansei-based color design for city map," ARSRIN, vol. 1, no. 3, 2001.

[5] N. K. Chuan, A. Sivaji, M. M. Shahimin, and N. Saad, "Kansei Engineering for e-commerce Sunglasses Selection in Malaysia," Procedia: Social and Behavioral Sciences, vol. 97, pp. 707-714, 2013.

[6] D. Joshi, R. Datta, E. Fedorovskaya et al., "Aesthetics and emotions in images," IEEE Signal Processing Magazine, vol. 28, no. 5, pp. 94-115, 2011.

[7] G. Zhang and E. Yu, "A novel personalized recommendation method in E-business based on kansei image," in Proceedings of the International Conference on Automation, Mechanical Control and Computational Engineering, Shunhe, China, April 2015.

[8] S. Smith and S.-H. Fu, "The relationships between automobile head-up display presentation images and drivers' Kansei," Displays, vol. 32, no. 2, pp. 58-68, 2011.

[9] Z. Tang, S. Sun, H. Guan, and Z. Yang, "The study and application of the product image survey and retrieval system based on kansei engineering," in Proceedings of the 13th International Conference on Computer-Aided Design and Computer Graphics (CAD/Graphics '13), pp. 453-454, November 2013.

[10] M. Ota and H. Aoyama, "Aesthetic design based on Kansei language," in Initiatives of Precision Engineering at the Beginning of a Millennium, pp. 917-921, Springer US, 2002.

[11] T. Luor, H.-P. Lu, H. Yu, and Y. Lu, "Exploring the critical quality attributes and models of smart homes," Maturitas, vol. 82, no. 4, pp. 377-386, 2015.

[12] H. C. Yadav, R. Jain, S. Shukla, S. Avikal, and P. K. Mishra, "Prioritization of aesthetic attributes of car profile," International Journal of Industrial Ergonomics, vol. 43, no. 4, pp. 296-303, 2013.

[13] Y.-C. Lee and S.-Y. Huang, "A new fuzzy concept approach for Kano's model," Expert Systems with Applications, vol. 36, no. 3, pp. 4479-4484, 2009. 
[14] M. Wu and L. Wang, "A continuous fuzzy Kano's model for customer requirements analysis in product development," Proceedings of the Institution of Mechanical Engineers, Part B: Journal of Engineering Manufacture, vol. 226, no. 3, pp. 535-546, 2012.

[15] L.-H. Chen and W.-C. Ko, "A fuzzy nonlinear model for quality function deployment considering Kano's concept," Mathematical and Computer Modelling, vol. 48, no. 3-4, pp. 581-593, 2008.

[16] C. Berger, R. Blauth, D. Boger et al., "Kano's methods for understanding customer defined quality," Center for Quality of Management Journal, vol. 2, no. 4, pp. 3-36, 1993.

[17] M. Hartono, K. C. Tan, and J. B. Peacock, Incorporating Kanos Model and Markov Chain into Kansei Engineering in Services, CRC Press, 2012.

[18] I. P. Tama, W. Azlia, and D. Hardiningtyas, "Development of customer oriented product design using kansei engineering and kano model: case study of ceramic souvenir," Procedia Manufacturing, vol. 4, pp. 328-335, 2015.

[19] C. Llinares and A. F. Page, "Kano's model in Kansei Engineering to evaluate subjective real estate consumer preferences," International Journal of Industrial Ergonomics, vol. 41, no. 3, pp. 233246, 2011.

[20] P. J. M. van Laarhoven and W. Pedrycz, "A fuzzy extension of Saaty's priority theory," Fuzzy Sets and Systems, vol. 11, no. 3, pp. 229-241, 1983.

[21] J.-C. Tu and C.-L. Hu, "Applying the fuzzy analytic hierarchy process to construct the product innovative service system of wedding photography apparel," Mathematical Problems in Engineering, vol. 2015, Article ID 171204, 12 pages, 2015.

[22] S. Banihashemi, E. Homayounvala, A. Talebpour et al., "Identifying and prioritizing evaluation criteria for user-centric digital identity management systems," International Journal of Advanced Computer Science \& Applications, vol. 7, no. 7, 2016.

[23] C.-C. Chyu and Y.-C. Fang, "A hybrid fuzzy analytic network process approach to the new product development selection problem," Mathematical Problems in Engineering, vol. 2014, Article ID 485016, 13 pages, 2014.

[24] H. M. Hsu and C. T. Chen, "Aggregation of fuzzy opinions under group decision-making," Fuzzy Sets and Systems, vol. 79, no. 3, pp. 279-285, 1996.

[25] J. Sanui and M. Inui, "Phenomenological approach to the evaluation of places: a study on the construct system associated with place evaluation," Journal of Architectural, Planning and Environmental Engineering, vol. 367, pp. 15-22, 1986.

[26] G. Kelly, The Psychology of Personal Constructs, Norton, New York, NY, USA, 1955.

[27] K.-S. Shen, "Measuring the sociocultural appeal of SNS games in Taiwan," Internet Research, vol. 23, no. 3, pp. 372-392, 2013.

[28] C.-H. Ho and K.-C. Hou, "Exploring the attractive factors of app icons," KSII Transactions on Internet and Information Systems, vol. 9, no. 6, pp. 2251-2270, 2015.

[29] J. Sanui, "Visualization of users requirements: Introduction of the evaluation grid method," in Proceedings of the 3rd Design and Decision Support Systems in Architecture and Urban Planning Conference, pp. 365-374, 1996.

[30] K. S. Shen, K. H. Chen, M. Y. Ma et al., "Measuring the functional and usable appeal of crossover B-car interiors," Human Factors \& Ergonomics in Manufacturing Service Industries, vol. 25, no. 1, pp. 106-122, 2015.

[31] J. J. Buckley, "Fuzzy hierarchical analysis," Fuzzy Sets and Systems, vol. 17, no. 3, pp. 233-247, 1985.
[32] T. L. Saaty, The Analysis Hierarchy Process: Planning, Priority Setting, Resource Allocation, McGraw-Hill, New York, NY, USA, 1980.

[33] C. C. Chen and M. C. Chuang, "Integrating the Kano model into a robust design approach to enhance customer satisfaction with product design," International Journal of Production Economics, vol. 114, no. 2, pp. 667-681, 2008.

[34] C. Hayashi, "On the quantification of qualitative data from the mathematico-statistical point of view," Annals of the Institute of Statistical Mathematics, vol. 2, no. 1, pp. 35-47, 1950.

[35] C. Iwabuchi et al., Data Management and Analysis by Yourself, Humura Publishing, 2001. 


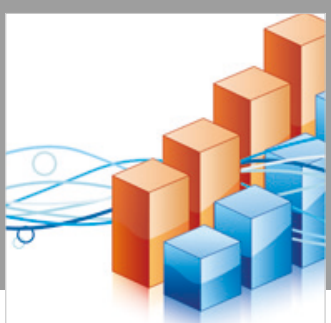

Advances in

Operations Research

\section{-n-m}
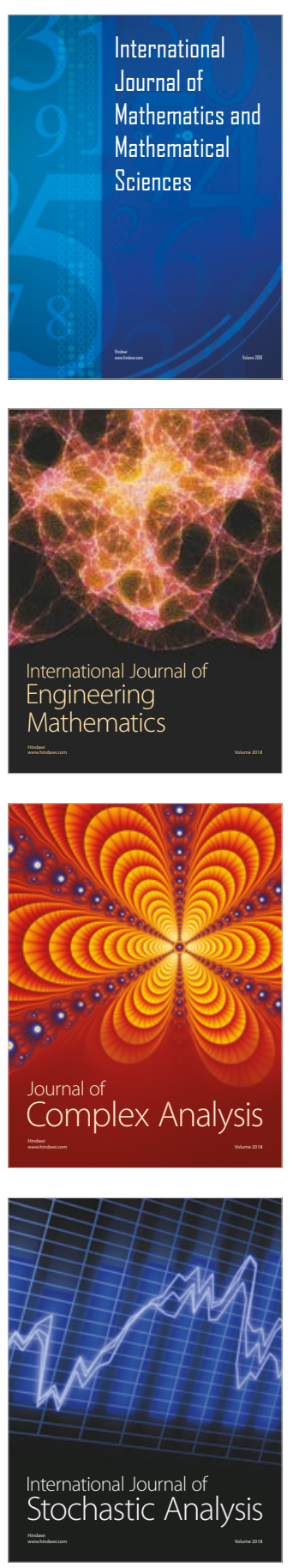
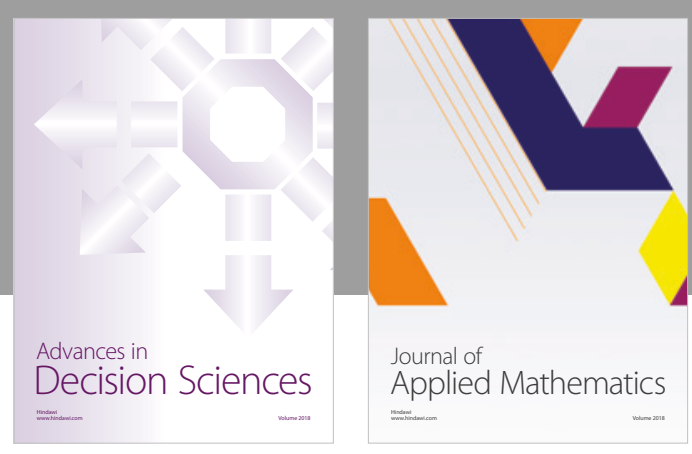

Journal of

Applied Mathematics
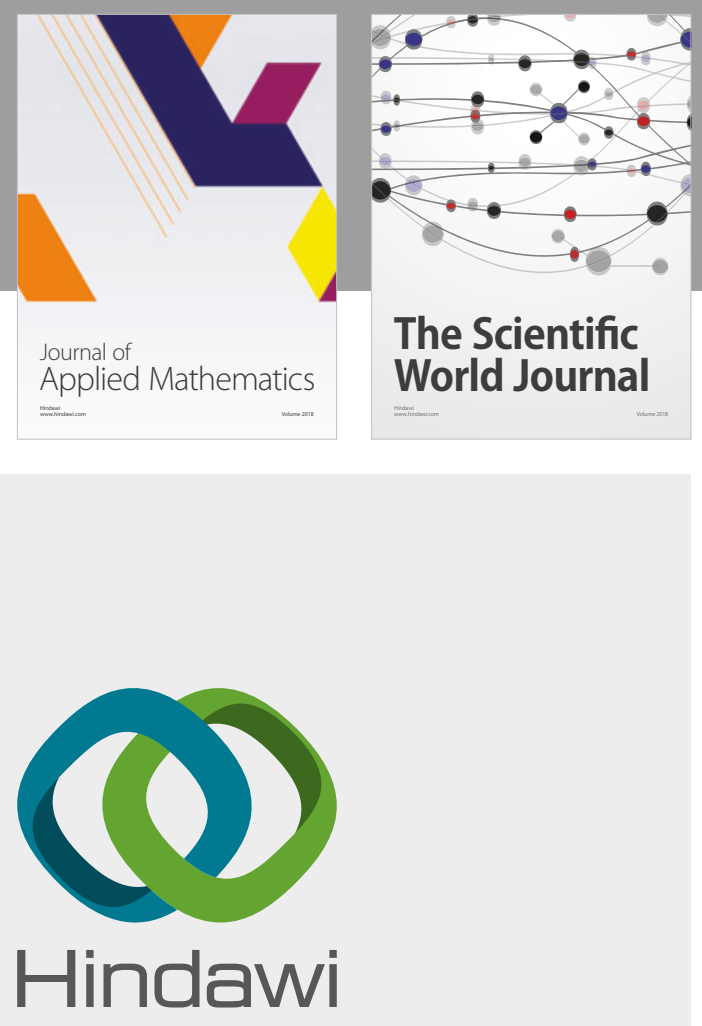

Submit your manuscripts at

www.hindawi.com

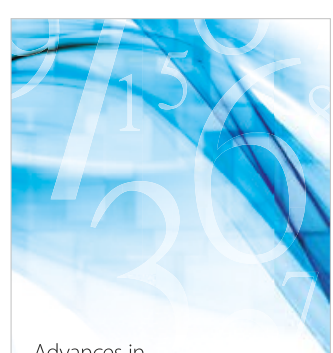

Advances in
Numerical Analysis
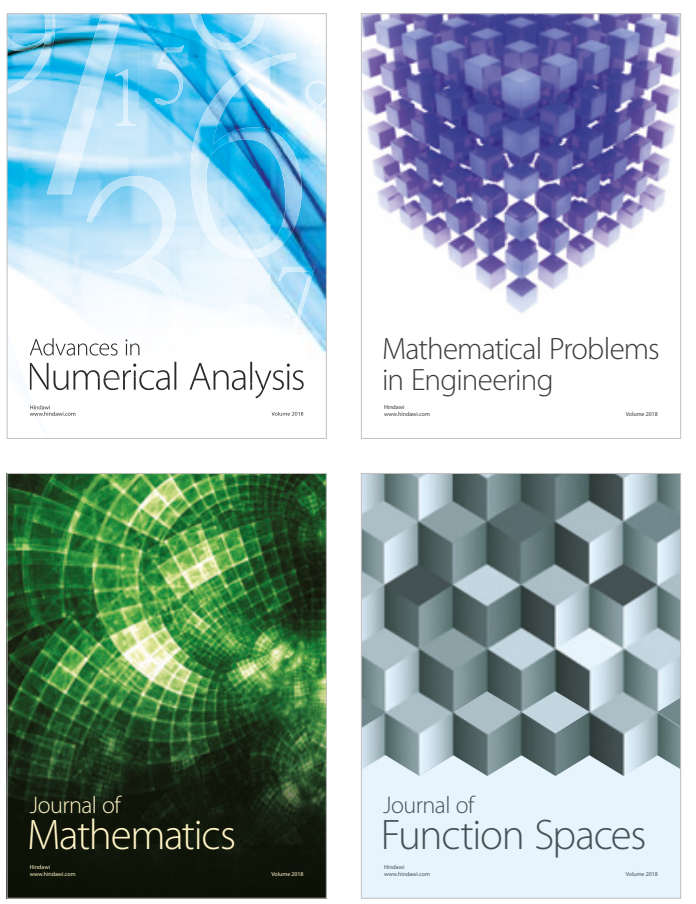

Mathematical Problems in Engineering

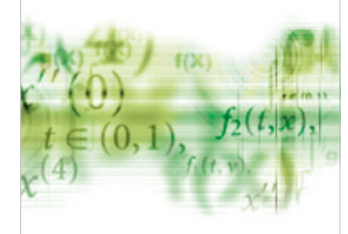

International Journal of

Differential Equations

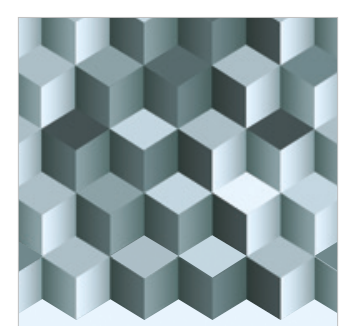

Journal of

Function Spaces

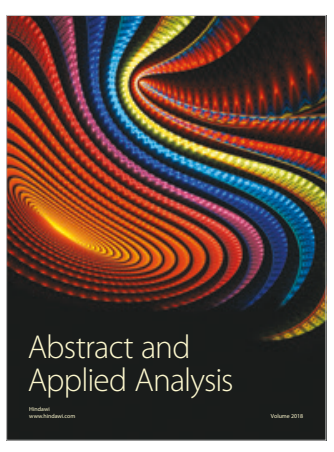

The Scientific

World Journal

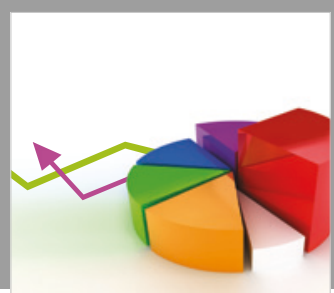

Journal of

Probability and Statistics
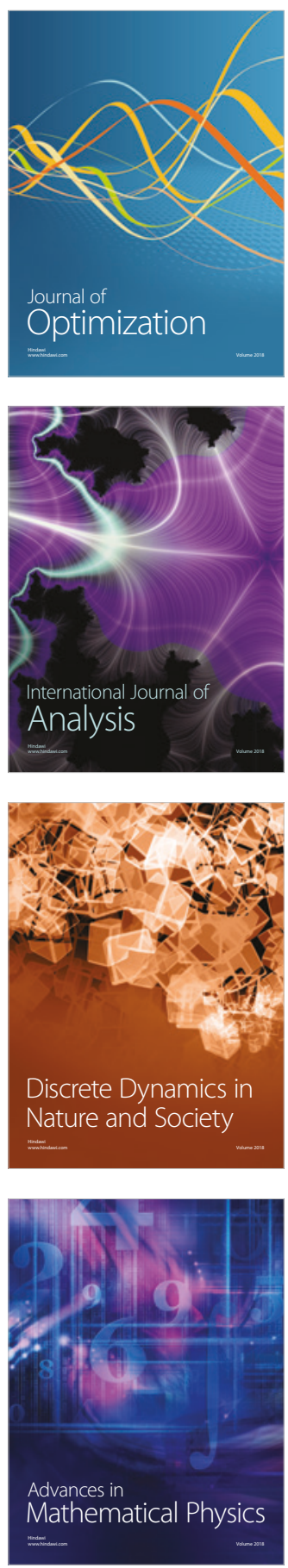